\title{
Kesejahteraan Subjektif pada Pemulung: Tinjauan Sosiodemografi
}

\author{
Sarah Hafiza ${ }^{1} \mathcal{E}$ Marty Mawarpury ${ }^{2}$ \\ 1,2Program Studi Psikologi, Fakultas Kedokteran, Universitas Syiah Kuala
}

\begin{abstract}
Subjective wellbeing is a negative or positive assessment of the experience experienced in all aspects of life. The purpose of this study was to identify the subjective welfare level of scavengers based on sociodemography. Using a quantitative approach with survey design methods and with incidental sampling techniques, the sample in the study involved 87 scavengers composed of 41 men and 46 women, aged 17-55 years, and domiciled in Banda Aceh. Subjective prosperity was measured using Satisfaction with Life Scale (SWLS) and Scale of Positive and Negative Experience (SPANE). The analysis methods used were descriptive statistics and chi square test for independent. The result of chi square statistic analysis showed that there was no correlation between subjective welfare of the scavengers in sociodemographic group (gender $p>0.05$; age $p>0.05$; last education $p>0.05$; marital status $p>0.05$; income $p>0.05$ ). The result of descriptive analysis showed that the dominant research subjects were at high subjective well-being level (58 subjects or $66,7 \%$ ).
\end{abstract}

Keywords: chi square; scavengers; sociodemography; subjective well-being

Abstrak. Kesejahteraan subjektif merupakan penilaian negatif ataupun positif terhadap pengalaman yang dialami pada seluruh aspek kehidupan. Tujuan penelitian ini untuk mengidentifikasi tingkat kesejahteraan subjektif pada pemulung berdasarkan sosiodemografi. Menggunakan pendekatan kuantitatif dengan metode survei dan dengan teknik sampling insidental, sampel dalam penelitian melibatkan 87 pemulung terdiri dari 41 laki-laki dan 46 perempuan, berusia 17-55 tahun, dan berdomisili di Banda Aceh. Kesejahteraan subjektif diukur menggunakan Satisfaction with Life Scale (SWLS) dan Scale of Positive and Negative Experience (SPANE). Analisis menggunakan statistik deskriptif dan chi square test for independent. Hasil analisis statistik chi square menunjukkan bahwa tidak terdapat hubungan tingkat kesejahteraan subjektif pemulung berdasarkan sosiodemografi (jenis kelamin $p>0,05$, usia $p>0,05$, pendidikan terakhir $p>0,05$, status pernikahan $p>0,05$, dan penghasilan $p>0,05)$. Subjek penelitian ini dominan berada pada tingkat kesejahteraan subjektif tinggi berjumlah 58 subjek $(66,7 \%)$.

Kata kunci: chi square; kesejahteraan subjektif; pemulung; sosiodemografi

Kepadatan penduduk merupakan salah satu penyebab timbulnya permasalahan sosial. Faktor dari masalah sosial adalah kemiskinan dan pengangguran (Nurnaningsih, 2017). Hal ini didukung dari data Badan Pusat Statistik (BPS) pada

${ }^{1}$ Korespondensi mengenai artikel ini dapat dilakukan melalui sarahhafiza96@gmail.com

ªtau melalui marty@unsyiah.ac.id tahun 2016 mencatat terdapat 27.760 .000 jiwa $(10,70 \%)$ penduduk miskin di Indonesia (Badan Pusat Statistik [BPS], 2017). Di Indonesia, Aceh termasuk salah satu provinsi yang memiliki permasalahan kemiskinan dan termasuk ke dalam sepuluh besar provinsi dengan angka kemiskinan tertinggi di Indonesia (Beritakini.co, 2017). Secara spesifik data BPS (2017) menyebutkan tingkat 
persentase kemiskinan di Aceh meningkat per Maret 2017 menjadi 872.610 jiwa $(16,89 \%)$.

Tingginya tingkat kemiskinan dan pengangguran menjadi sebab akibat dari permasalahan ekonomi saat ini. Permasalahan ekonomi ini akan menghambat terwujudnya kesejahteraan pada masyarakat (Satrio, 2014). Menurut Fitrah, Isnaini, dan Asshary (2017) beberapa individu memilih bekerja menjadi pemulung sebagai alternatif agar tidak menjadi pengangguran. Pekerjaan tanpa keahlian khusus ini berada pada kasta terakhir dalam kemiskinan, karena para pemulung tidak dapat menemukan jenis pekerjaan lainnya (Devi, 2017). Dalam hierarki pekerjaan informal, bekerja sebagai pemulung berada pada urutan yang paling rendah dan kebanyakan yang bekerja adalah laki-laki dan perempuan yang belum termasuk lansia, serta anakanak.

Menurut Shalih (2003) pemulung adalah orang yang memungut, mengambil, mengumpulkan, dan mencari sampah, baik perorangan atau kelompok. Selain itu, menurut Permatasari dan Rahdriawan (2013) dan Kementerian Sosial Republik Indonesia (2018) pemulung adalah golongan sosial yang memiliki usaha mengumpulkan dan memungut barang bekas. Para pemulung mengambil berbagai barang bekas yang berasal dari jalan, tempat pembuangan sampah, pekarangan rumah penduduk, pasar, dan tempat lainnya. Sebagian barang bekas yang dikumpulkan oleh pemulung berasal dari kumpulan sampah.

Bekerja sebagai pemulung dapat memberikan dampak positif maupun negatif untuk dirinya sendiri maupun orang lain. Salah satu dampak positif bekerja sebagai pemulung untuk dirinya sendiri yaitu mendapatkan pekerjaan yang baik tanpa harus melakukan perilaku yang menyimpang (meminta atau mencuri) serta mendapatkan penghasilan (Khiththati, 2008; Magdalena, 2015). Manfaat bekerja sebagai pemulung untuk lingkungan sekitarnya yaitu dapat mengurangi jumlah sampah yang ada di kota dan sekaligus mengelompokkan sampah berdasarkan jenisnya (Pardede, 2017). Dampak negatif bekerja sebagai pemulung yaitu selalu mendapatkan stigma dari masyarakat dan juga pemulung rentan terhadap berbagai penyakit karena tempat kerja dan tempat tinggal yang tidak bersih dan sebagai sarang penyakit (Azhari, 2009; Taufik, 2013; Suhartono, 2013).

Kondisi positif maupun negatif yang dialami pemulung akan berdampak pada kesejahteraan subjektifnya. Menurut Diener (2000), kesejahteraan subjektif dapat diartikan sebagai pengalaman setiap individu, baik penilaian negatif atau positif secara khas mencakup pada penilaian dari seluruh aspek kehidupan. Individu yang mempunyai kesejahteraan subjektif yang rendah, akan memandang hidup secara negatif, menganggap peristiwa yang terjadi sebagai hal yang tidak menyenangkan, kurangnya kasih sayang, sering merasa tidak puas dengan apa yang telah didapatkan sehingga timbul emosi seperti kecemasan, depresi, dan kemarahan (Myers \& Diener, 1995; Diener, 2000). Menurut Diener, Oishi, dan Lucas (2003) bahwa pada dasarnya, inti dari kehidupan yang baik adalah pada saat individu mencintai, menyukai kehidupannya, optimis, semangat dan penuh keyakinan yang merupakan bagian dari komponen afek positif.

Banyak hal yang dialami para pemulung dan mudah untuk mengasumsikan bahwa para pemulung tidak mendapatkan sumber kebahagiaan (Hoeur, 2018). Menurut Schkade dan Kahneman (1998) hal ini disebut sebagai "focusing effect", yang mana masyarakat terlalu fokus melihat pemulung pada hal- 
hal yang negatif, sehingga mengabaikan konteks kehidupan dan kesejahteraan subjektifnya, seperti: teman, hubungan romantis, dan religiusitas. Oleh karena itu, dalam penelitian ini ingin mengidentifikasi tingkat kesejahteraan subjektif pemulung berdasarkan sosiodemografi.

Diener dan Tov (2013) mendefinisikan kesejahteraan subjektif sebagai cara individu mengevaluasi dirinya dan pengalaman yang terjadi dalam kehidupannya. Di sisi lain, kesejahteraan subjektif lebih dikenal dengan kebahagiaan, hal tersebut dikarenakan perasaan positif menjadi suatu hal yang penting bagi aspek kesejahteraan, meliputi perasaan positif yang lebih.

Kesejahteraan subjektif memiliki tiga komponen, pertama kepuasan hidup (life satisfaction) yang diartikan sebagai penilaian kognitif individu secara global mengenai kehidupannya dan suatu penilaian dalam diri individu, yang terdiri dari kepuasan yang dirasakan dalam berbagai bidang kehidupan. Kedua afek menyenangkan (positive affect), Diener mengatakan bahwa afeksi positif ditandai dengan mengalami emosi-emosi dan suasana hati yang menyenangkan, dan terakhir afek yang tidak menyenangkan (negative affect) merupakan kombinasi dari dorongan dan hal-hal yang tidak menyenangkan termasuk suasana hati yang dapat dipisahkan menjadi emosi dan mood khusus.

Selain tiga komponen, Diener (1984) menjelaskan bahwa terdapat enam faktor yang memengaruhi kesejahteraan subjektif, beberapa di antaranya adalah kepuasan subjektif (Campbell, 1981), penghasilan (Eddington \& Shuman, 2005), variabel demografis lainnya (seperti, usia (Ramzan \& Rana, 2014), jenis kelamin (Wirawan, 2010), pekerjaan (Weiten, 2008), pendidikan (Eddington \& Shuman, 2005), dan status perkawinan (Sahlan, 2012), perilaku dan hasil (Gore, dalam Hikmatunnisa \& Takwin, 2007), kepribadian (Giyati \& Wardani, 2016), dan pengaruh biologis atau kesehatan (Mehnert, Krauss, Nadler, \& Boyd. 1990).

\section{Metode}

\section{Identifikasi variabel}

Kesejahteraan subjektif merupakan kondisi yang mengacu pada evaluasi individu terhadap hidupnya, yang dilakukan secara kognitif dan afektif. Bentuk evaluasi kognitif dari individu adalah kepuasan menyeluruh terhadap kehidupannya, sedangkan evaluasi afektif terlihat dengan lebih seringnya dirasakan afek positif seperti kesenangan dan kebahagiaan serta lebih sedikit mengalami afek negatif seperti kesedihan dan kemarahan.

\section{Subjek dan lokasi penelitian}

Pengambilan sampel menggunakan nonprobability sampling dengan teknik sampling insidental. Subjek dalam penelitian ini berjumlah 87 pemulung (41 laki-laki dan 46 perempuan). Penelitian dilakukan di beberapa wilayah di Kota Banda Aceh. Adapun kriteria subjek penelitian adalah orang yang mengumpulkan atau memungut barang bekas di berbagai tempat untuk mencari nafkah, tidak memiliki pekerjaan tetap, dan berusia 15 tahun ke atas. Berdasarkan BPS (2018) penduduk yang termasuk angkatan kerja adalah penduduk usia kerja (15 tahun dan lebih) yang bekerja, kecuali yang masih sekolah.

\section{Instrumen pengukuran}

Pengukuran kesejahteraan subjektif dalam penelitian menggunakan dua skala yaitu Satisfaction with Life Scale (SWLS) yang mengukur aspek kognitif (kepuasan hidup) yang terdiri dari 5 aitem dengan 7 pilihan jawaban. Total skor tertinggi sebesar 35 dan skor terendah 5. Scale of 
Positive and Negative Experience (SPANE) untuk mengukur aspek afektif (afek positif \& afek negatif) yang berjumlah 12 aitem terbagi menjadi 6 aitem emosi positif dan 6 aitem emosi negatif dengan 5 pilihan jawaban. Total skor tertinggi sebesar 60 dan skor terendah 12. Diener (2000) menjelaskan bahwa pengukuran kesejahteraan subjektif tidak dapat diukur hanya dengan menggunakan satu skala, hal tersebut dikarenakan masing-masing skala mengukur dimensi yang berbeda. Nilai reliabilitas alpha Cronbach pada SWLS sebesar 0,742 dan pada SPANE-P (positif) sebesar 0,970, SPANE-N (negatif) sebesar 0,841, serta pada SPANE-B (seimbang) menunjukkan nilai reliabilitas 0,897 .

Tabel 1.

Data Demografi Subjek Penelitian

\begin{tabular}{lcc}
\multicolumn{1}{c}{ Deskripsi } & Jumlah subjek (\%) & Total (\%) \\
\hline Jenis Kelamin & $41(47,1 \%)$ & \\
Laki-Laki & $46(52,9 \%)$ & \\
Perempuan & & \\
Usia & $18(20,7 \%)$ & \\
17-25 Tahun & $26(29,9 \%)$ & 100 \\
26-35 Tahun & $27(31 \%)$ & \\
36-45 Tahun & $15(17,2 \%)$ & \\
46-55 Tahun & & 100 \\
Pendidikan Terakhir & $13(14,9 \%)$ & \\
SD & $36(41,4 \%)$ & \\
SMP & $38(43,7 \%)$ & \\
SMA/ Sederajat & & 100 \\
Status Pernikahan & $69(79,3 \%)$ & \\
Menikah & $20,7(20,7 \%)$ & \\
Belum Menikah/ Duda/ Janda & & \\
Penghasilan & & \\
Rp1.000-Rp75.000/ hari & & \\
Rp76.000-Rp150.000/ hari & $54(62,1 \%)$ & \\
\hline
\end{tabular}

Analisis data

Metode analisis data yang digunakan dalam penelitian ini menggunakan analisis deskriptif dan pengolahan data menggunakan analisis crosstab dan teknik chi-square test for independence.

\section{Hasil}

Pengambilan data dilakukan di beberapa wilayah di Banda Aceh yang berjumlah 87 subjek, terdiri dari 41 (47,1\%) laki-laki dan $46(52,9)$ perempuan. Adapun rentang usia subjek penelitian dominan berada pada rentang usia 26-35 tahun, di mana terdapat 26 subjek (29,9\%). Untuk tingkat pendidikan terakhir, didominasi oleh tingkatan SMA/ Sederajat yaitu sebesar 38 $(43,7 \%)$. Status pernikahan menunjukkan terdapat $69(79,3 \%)$ subjek telah menikah 
Tabel 2.

Chi Square Test for Independent

\begin{tabular}{|c|c|c|c|}
\hline \multicolumn{2}{|l|}{ Chi Square Test for Independent } & \multicolumn{2}{|c|}{ Kategorisasi $(N=87)$} \\
\hline Sosiodemografi & $\begin{array}{c}\text { Asymp. Sig. } \\
\text { (2-sided) }\end{array}$ & Tinggi & Rendah \\
\hline Kesejahteraan subjektif*Jenis kelamin & 0,761 & & \\
\hline Laki-Laki & & 28 & 13 \\
\hline Perempuan & & 30 & 16 \\
\hline Kesejahteraan subjektif*Usia & 0,702 & & \\
\hline 17-25 Tahun & & 14 & 4 \\
\hline 26-35 Tahun & & 17 & 9 \\
\hline 36-45 Tahun & & 16 & 11 \\
\hline 46-55 Tahun & & 11 & 5 \\
\hline subjektif*Pendidikan & 0,057 & & \\
\hline Terakhir & & 9 & 4 \\
\hline $\mathrm{SD}$ & & 19 & 17 \\
\hline SMP & & 30 & 8 \\
\hline SMA/ Sederajat & & & \\
\hline Kesejahteraan subjektif*Status Pernikahan & 0,574 & & \\
\hline Menikah & & 45 & 24 \\
\hline Belum Menikah/ Duda/ Janda & & 13 & 5 \\
\hline Kesejahteraan subjektif*Penghasilan & 0,639 & & \\
\hline Rp1.000-Rp75.000/ hari & & 37 & 17 \\
\hline Rp76.000-Rp150.000/ hari & & 21 & 12 \\
\hline
\end{tabular}

dan 20,7 (20,7\%) subjek belum menikah/ duda/ janda. Sementara berdasarkan jumlah penghasilan yang didapatkan bahwa rata-rata penghasilan yang didapat perhari yaitu berada pada rentang Rp1.000-Rp150.000 sebanyak 54 (62,1\%) subjek. Data-data subjek penelitian yang diperoleh dapat dilihat pada Tabel 1 (lihat halaman 144).

Hasil analisis statistik chi square (lihat tabel 2) menunjukkan bahwa tidak terdapat hubungan tingkat kesejahteraan subjektif pemulung ditinjau dari sosiodemografi (jenis kelamin $p=0,761$, usia $p=0,702$, pendidikan terakhir $p=$
0,057, status pernikahan $p=0,574$, dan penghasilan $p=0,639$ ).

\section{Diskusi}

Berdasarkan hasil analisis secara deskriptif menunjukkan bahwa subjek penelitian dominan berada pada tingkat kesejahteraan subjektif tinggi. Sebanyak 58 subjek dalam kategorisasi tingkat tinggi dan sebanyak 29 subjek lainnya berada pada tingkat kesejahteraan subjektif rendah. Tidak terdapatnya hubungan antara tingkat kesejahteraan subjektif ditinjau dari sosiodemografi (jenis 
kelamin, usia, pendidikan, status pernikahan, dan penghasilan) pada individu dapat disebabkan oleh beberapa faktor. Menurut Diener (1984) yang dapat memengaruhi kesejahteraan subjektif dalam diri individu, misalnya kepuasan subjektif, penghasilan, usia, jenis kelamin, budaya, agama, pekerjaan, pendidikan, pernikahan, dan kepribadian.

Hasil analisis statistik tidak menunjukkan adanya hubungan antara tingkat kesejahteraan subjektif dengan jenis kelamin pada pemulung. Menurut Diener dan Tay (2015) tidak ada perbedaan tingkat kesejahteraan subjektif pada lakilaki maupun perempuan. Hal ini sejalan dengan penelitian sebelumnya yang dilakukan oleh Forest (1996); Eddington dan Shuman (2005); Utami (2009) (kesejateraan subjektif mahasiswa) serta Miranda dan Amna (2016) (kesejateraan subjektif pada dewasa awal), yang menemukan tidak adanya perbedaan kesejahteraan subjektif antara laki-laki dan perempuan. Menurut Forest (1996) hal tersebut dikarenakan dalam merespon peristiwa hidup yang tidak diinginkan laki-laki dan perempuan tidak memiliki perbedaan. Hasil temuan dilapangan juga menunjukkan hal yang sama, bahwa yang bekerja sebagai pemulung tidak hanya laki-laki, namun perempuan juga bekerja mencari-cari barang bekas untuk membantu perekonomian keluarganya.

Usia rata-rata subjek penelitian yaitu pada rentang 26-45 tahun. Hasil analisis statistik tidak menunjukkan adanya hubungan yang signifikan antara tingkat kesejahteraan subjektif dengan usia pada pemulung. Tetapi, dari 53 subjek pada rentang usia tersebut banyak diantaranya yang memiliki tingkat kesejahteraan subjektif yang baik. Menurut Ramzan dan Rana (2014) perbedaan usia berkaitan dengan kesejahteraan subjektif individu, dimana pada usia yang lebih muda memiliki tingkat kebersyukuran yang lebih baik yang berhubungan dengan kepuasan hidup individu. Para pemulung merasa senang bekerja karena dapat membantu perekonomian keluarga dengan bekerja mengumpulkan barang bekas, ditambah lagi menurut Hurlock (2009) pada tahap perkembangan ini sudah waktunya untuk bekerja. Walaupun sebenarnya para pemulung menginginkan pekerjaan yang lebih layak lagi dibandingkan bekerja mencari barang bekas (Hurlock, 2009).

Berdasarkan tingkat pendidikan, tidak terdapat hubungan tingkat kesejahteraan subjektif dengan pendidikan. Namun, hasil penelitian menunjukkan subjek yang memiliki tingkat pendidikan SMP dan SMA/ sederajat berjumlah 36 dan 38 subjek, ratarata memiliki tingkat kesejahteraan subjektif yang tinggi, dimana 49 subjek berada pada tingkat kesejahteraan subjektif tinggi dan 25 subjek lainnya pada tingkat rendah. Hasil wawancara singkat dengan para pemulung juga menunjukkan hal yang sama. Banyak diantara para pemulung yang putus sekolah akibat kemiskinan dan harus bekerja untuk memenuhi kehidupan keluarganya. Walaupun keinginan untuk belajar masih ada, tetapi bekerja adalah hal yang masih diprioritaskan pada saat ini. Disisi lain, ada beberapa pihak yang memberikan edukasi gratis setiap minggu untuk anak-anak pemulung, khususnya di Gampong Jawa, Banda Aceh.

Kegiatan edukasi kepada anak-anak pemulung ini diberi nama "Taman Edokasi Anak Pemulung", yang mana jumlah anak yang belajar setiap harinya terus meningkat. Walaupun hanya beralaskan tikar tetapi anak-anak tetap belajar penuh gembira (Oktaviano, 2018). Para relawan tidak hanya memberikan bantuan edukasi, namun juga memberikan bantuan berupa materi. Bantuan yang didapatkan tidak hanya dari satu atau dua relawan, terkadang bantuan dari pemerintah dan 
LSM juga ada (misal, pada bulan puasa, menjelang hari raya, dan kegiatan sosial lainnya). Menurut Hoeur (2018) bantuan yang diberikan orang lain juga dapat memberikan kontribusi pada kesejahteraan subjektif individu.

Hasil penelitian menunjukkan bahwa sebanyak 69 subjek yang berstatus menikah memiliki tingkat kesejahteraan subjektif lebih tinggi dibandingkan dengan yang belum menikah. Hal ini didukung oleh pernyataan Diener dan Biswas-Diener (2000) yang menyatakan bahwa individu yang telah menikah memiliki kesejahteraan subjektif yang lebih tinggi dibandingkan dengan yang belum menikah, hal ini dikarenakan individu yang telah menikah memiliki integrasi sosial dan dukungan sosial yang lebih tinggi dibandingkan yang belum menikah. Lebih lanjut, Sahlan (2012) menambahkan bahwa individu yang menikah dan bekerja dapat meningkatkan kesejahteraan subjektif dalam dirinya, hal ini dikarenakan individu tersebut mampu memenuhi kebutuhan dirinya sendiri dan juga pasangannya. Hal ini dapat meningkatkan keharmonisan dalam diri dan pasangannya serta meminimalisasi terjadinya konflik antar pasangan. Berdasarkan data demografi subjek juga dapat dilihat bahwa sebagian besar subjek penelitian selain berstatus menikah juga berstatus sebagai pekerja, yaitu pemulung. Sehingga dapat disimpulkan bahwa status menikah dan juga bekerja sebagai pemulung dapat memengaruhi tingkat kesejahteraan subjektif pemulung pada tingkat kategorisasi tinggi. Namun, dari hasil analisis data tidak terdapat hubungan yang signifikan antara tingkat kesejahteraan subjektif dengan status pernikahan pada pemulung.

Penghasilan rata-rata subjek yang memiliki kesejahteraan subjektif lebih tinggi yaitu sebanyak $54(62,1 \%)$ dari 87 subjek dengan rentang $\mathrm{Rp}$ 1.000,00-Rp
75.000,00 per hari. Penghasilan yang didapatkan para pemulung kurang dari Upah Minimum Provinsi (UMP) Kota Banda Aceh 2018 yaitu Rp 2.700.000,00 per bulan. Tetapi setiap hari pemulung akan mendapatkan penghasilan, walaupun dengan jumlah yang berbeda-beda. Penghasilan yang didapatkan pemulung setiap harinya hanya cukup untuk makan saja. Namun bagi para pemulung bekerja sebagai pemulung memiliki nilai positif dibandingkan pekerjaan lainnya. Bekerja menjadi pemulung tidak bergantung pada orang lain, bekerja tanpa perintah dan tekanan dari atasan, waktu bekerja yang fleksibel dan bisa menghabiskan dengan keluarga atau teman kapan saja, serta tanpa adanya kontrol dari luar. Faktorfaktor tersebut merupakan bagian dari faktor interpersonal yang dapat memengaruhi kesejahteraan subjektif seseorang (Houer, 2018).

Bekerja sebagai pemulung cukup untuk memenuhi kebutuhan dasar setiap harinya dan kebutuhan dasar ini menjadi faktor yang penting dalam menentukan kebahagiaan pemulung. Hal ini sesuai dengan yang dikatakan Diener (1984) bahwa individu yang memiliki sumber daya keuangan yang memadai akan memiliki kesejahteraan subjektif yang tinggi. Banyak hasil penelitian Diener yang mengatakan bahwa semakin banyak penghasilan yang didapatkan maka akan semakin tinggi pula kesejahteraan subjektifnya. Namun, pada beberapa negara yang menganut sistem kolektivis akan memiliki tingkat kesejahteraan subjektif yang tinggi walaupun mendapatkan penghasilan dalam kategori rendah, karena adanya kerukunan dalam keluarga (Diener, Harter, \& Arora, 2010; Hoeur (2018).

Telaah lebih lanjut ditinjau dari faktor lainnya yang memengaruhi tingkat kesejahteraan subjektif adalah agama dan budaya. Menurut Diener (1984) agama dan 
budaya merupakan salah satu faktor yang memengaruhi kesejahteraan subjektif. Secara umum, religiusitas individu cenderung dapat meningkatkan kesejahteraan subjektif yang lebih tinggi, seperti doa dan beribadah juga telah dikaitkan dengan kesejahteraan subjektif yang lebih tinggi (Diener \& Ryan, 2009). Hal ini juga dibuktikan dari hasil observasi dari lapangan, yaitu hampir semua subjek beragama Islam dan memercayai bahwa apa yang dikerjakan saat ini adalah rezeki dari Yang Maha Kuasa:

"Alhamdulillah masih bisa bekerja, diberi Allah kesempatan untuk mencari uang walaupun bekerja disampah-sampah seperti ini. Yang penting kita harus tetap bersyukur dan solat aja dek, mungkin Allah sudah punya rencana lain dibalik ini." (S-H)

Berdasarkan budaya, menurut Samad (2017) agama Islam merupakan identitas masyarakat Aceh, sehingga agama Islam menjadi jalan hidup yang menetap dalam sebuah sistem dan struktur sosial yang akan dijadikan pandangan hidup. Lebih lanjut, Umami (2009) menjelaskan bahwa Aceh dikenal memiliki budaya dengan nilai-nilai agama yang kuat, sikap, dan watak yang keras dalam menghadapi masalah kehidupan, dan sabar serta ikhlas terhadap hal-hal yang merupakan kehendak dari Tuhan.

Hal ini didukung dari hasil wawancara yang dilakukan peneliti kepada pemulung yang tinggal di Gampong Jawa dan sudah bekerja sebagai pemulung selama 3 tahun belakangan. $\mathrm{H}$ berjenis kelamin perempuan dan mulai bekerja sejak kakinya yang patah akibat kecelakaan. Subjek $\mathrm{H}$ tetap bersyukur dengan keadaan yang dijalani saat ini, walaupun hidup serba kekurangan tetapi tidak pernah lupa untuk beribadah kepada
Allah. Pada saat peneliti menanyakan beberapa pertanyaan terkait dengan aitem alat ukur, subjek menjawab sambil menceritakan tentang kehidupannya. Subjek mengatakan hidup yang dijalaninya semakin sulit sejak suaminya meninggal, namun $\mathrm{H}$ tetap berusaha setiap harinya untuk tetap bekerja dan beribadah. Kesembuhan yang $\mathrm{H}$ dapatkan merupakan kesempatan hidup kedua baginya, maka dari itu setiap harinya $\mathrm{H}$ tidak pernah lupa untuk mensyukuri segala nikmat yang didapatkan.

Para pemulung memiliki kemampuan untuk dapat memberikan pandangan yang berbeda dari realita dalam memahami yang dihadapi, walaupun tidak dapat mengubah realita tersebut. Hal ini dikarenakan adanya kepercayaan bahwa ini adalah rezeki yang diberikan oleh Yang Maha Kuasa. Menurut Brickman, Coates, dan Janoff-Bullman (1978) hal ini mencerminkan proses adaptasi yang mengatakan bahwa manusia beradaptasi dengan keadaan mereka untuk mempertahankan titik kebahagiaan yang sedikit dipengaruhi oleh lingkungannya.

Memiliki keluarga yang penuh kasih sayang dan perhatian ternyata merupakan faktor penting dalam menentukan kebahagiaan. Hasil observasi pada saat penelitian juga menunjukkan hal yang sama, dimana para pemulung mengumpulkan atau membersihkan barang bekas bersama-sama dengan anggota keluarganya (bersama anak, saudara, ataupun pasangan). Dalam keluarga juga dibutuhkan keterbukaan agar dapat saling memahami satu sama lain sehingga mengurangi adanya gesekan antar anggota keluarga juga akan menciptakan kebahagiaan (Hoeur, 2018).

Berdasarkan hasil analisis statistik penelitian, terlihat bahwa tidak adanya hubungan antara tingkat kesejahteraan subjektif pemulung ditinjau berdasarkan sosiodemografi. Namun demikian, hasil 
analisa yang dilakukan secara deskriptif, menunjukkan bahwa lebih dari 50\% subjek penelitian berada pada kategorisasi kesejahteraan subjektif tingkat tinggi. Hal ini disebabkan karena beberapa faktor yang memengaruhi tingkat kesejahteraan subjektif pada pemulung.

\section{Kesimpulan}

Menurut Hoeur (2018) kesejahteraan subjektif dari para pemulung ditentukan pada persepsi mengenai kehidupan bersama keluarga, bagaimana berhubungan dengan teman-teman di tempat pengumpulan barang bekas, bagaimana dengan perasaan puas atas makanan yang dimakan setiap harinya, dan bagaimana para pemulung menemukan kebahagiaan dan kepuasan untuk memenuhi kebutuhan dasar. Cara berpikir para pemulung, apa yang dialami dari lingkungan sekitar, dan sikap serta penilaian hidup juga menentukan kesejahteraan subjektif para pemulung. Lebih lanjut Hoeur mengatakan bahwa kesejahteraan subjektif pada pemulung sangat bergantung pada budaya, artinya budaya berperan penting dalam menentukan kesejahteraan subjektif individu berdasarkan konsep dan faktorfaktor tertentu. Disisi lain, hasil penelitian yang dilakukan yang sesuai dengan definisi kesejahteraan subjektif adalah bahwa adanya penilaian atas kepuasan hidup yang merupakan bagian dari pengalaman subjektif secara fenomenologis (Diener, 1984; 2006; Cropanzano \& Wright, 2001). Individu bahagia ketika secara subjektif percaya dirinya bahagia. Selama bersama keluarga ataupun orang terdekat para pemulung tetap merasakan kegimbiraan dan mengesampingkan apa yang dihadapi saat ini. Persahabatan atau kekeluargaan telah diindentifikasi sebagai prediktor tingginya kesejahteraan subjektif dalam budaya kolektivis (Markus \& Kitayama, 1991). Penentuan kebahagiaan juga ditentukan dari budaya yang ada.

\section{Saran}

Berdasarkan hasil penelitian ada beberapa saran yang diajukan, yaitu: (1) kepada peneliti selanjutnya yang ingin melakukan penelitian dengan variabel yang sama, maka dapat diteliti menggunakan metode kualitatif melalui observasi dan wawancara untuk memperdalam hasil variabel penelitian, terutama berkaitan dengan dinamika atau gambaran kesejahteraan subjektif pada pemulung. Penelitian juga dapat dilakukan tidak hanya kepada pemulung, tetapi bisa dibandingkan dengan pengemis ataupun individu yang memiliki kriteria serupa. (2) Peneliti merasa penelitian ini memiliki beberapa kekurangan yaitu peneliti tidak membahas secara mendalam terkait faktorfaktor yang mempengaruhi kesejahteraan subjektif seperti budaya, agama, dan tempat pemulung berdomisili, serta faktor lainnya yang dapat memengaruhi variabel yang tidak terjelaskan dalam penelitian ini. Selain itu, keterbatasan tempat penelitian yang hanya di Banda Aceh serta jumlah sampel yang sedikit juga menjadi kelemahan dalam penelitian ini.

\section{Kepustakaan}

Azhari, S, K. (2009). Sketsa masyarakat pemulung kota Bandung. Jurnal Sosioteknologi, 17(8), 696-701.

Badan Pusat Statistik. (2018). Tenaga KerjaBadan Pusat Statistik. Diakses melalui

https://www.bps.go.id/subject/6/tena ga-kerja.html (pada Maret 2018)

Badan Pusat Statistik. (2017). Profil Kemiskinan Di Indonesia September 2016. Diakses melalui 112 Perwira \& Meiyanto Memah ami.docx 
Beritakini.co. (2017). 'Naik kelas', Aceh jadi provinsi termiskin di Sumatera. Berita Kini. Diakses melalui http://beritakini.co/news/naik-kelasaceh-jadi-provinsi-termiskin-disumatera/index.html (pada 23 Januari 2018)

Brickman, P., Coates, D., \& Janoff Bulman, R. (1978). Lottery winners and accident victims: Is happiness relative? Journal of Personality and Social Psychology, 36(8), 917-927. doi: 10.1037/0022-3514.36.8.917

Campbell, A., Converse, P, E., \& Rodgers, W, L. (1976). The quality of American life. New York: Russell Sage Foundation.

Cropanzano, R., \& Wright, T. (2001). When a "happy" worker is really a "productive" worker: A review and further refinement of happy productive worker thesis. Journal of Consulting Psychology: Practice and Research, 53(3), 182-199. doi: 10.1037/1061-4087.53.3.182

Devi, S. (2017). Surviving on waste: A study of waste pickers. International Journal of Academic Research and Development, 2(6), 1229-1232.

Diener, E. (1984). Subjective well-being. Psychological Bulletin, 95, 542-575.

Diener, E. (2000). Subjective well-being: The science of happiness and a proposal for a national index. American Psychologist Journal, 55(1), 34-43. doi: 10.1037/0003-066X.55.1.34

Diener, E. (2006). Guidelines for national indicators of subjective well-being and ill-being. Journal of Happiness Studies, 7(4), 397-404. doi: 10.1007/s11482-006-9007-x

Diener, E., \& Biswas-Diener, R. (2000). New directions in subjective wellbeing research: The cutting edge. Indian Journal of Clinical Psychology, 27(1), 21-33.
Diener, E., \& Ryan, K. (2009). Subjective well-being: A general overview. South African Journal of Psychology, 39(4), 391-406. doi: 10.1177/2F008124630903900402

Diener, E., \& Tay, L. (2015). Subjective well-being and human welfare around the world as reflected in the Gallup World Poll. International Journal of Psychology, 50(2), 135-149. doi: 10.1002/ijop.12136

Diener, E., \& Tov, W. (2013). Subjective well-being. Research Collection School of Social Sciences, 1-8. doi: 10.1002/9781118339893.wbeccp518

Diener, E., Harter, J., \& Arora, R. (2010). Wealth and happiness across the world: Material prosperity predicts life evaluation, whereas psychosocial prosperity predicts positive feeling. Journal of Personality and Social Psychology, 99(1), 52-61. doi: $\underline{10.1037 / \mathrm{a} 0018066}$

Diener, E., Oishi, S., \& Lucas, R, E. (2003). Personality, culture, and subjective well-being: Emotional and cognitive evaluation of life. Annual Reviews Psychology. 54, 403-425. doi: 10.1146/annurev.psych.54.101601.145 $\underline{056}$

Eddington, N., \& Shuman, R. (2005). Subjective well-being (happiness). San Diego, CA: Continuing Psychology Education.

Fitrah, A, S., Isnaini., \& Assahary, S. (2017). Diskriminasi warga terhadap pemulung. Diakses melalui http://jim.stkip-pgrisumbar.ac.id/prodi/XP?page $=14$ (pada 19 Desember 2017)

Forest, K. B. (1996). Gender and the pathways to subjective well-being. Social Behavior and Personality, 24(1), 19-34. doi: 10.2224/sbp.1996.24.1.19

Giyati \& Wardani, I. R. K. (2016). Ciri-ciri kepribadian dan kepatutan sosial sebagai prediktor subjective wellbeing (kesejahteraan subyektif) pada 
remaja akhir. Analitika, 8(1), 10-24. doi: $\underline{10.31289 / a n a l i t i k a . v 8 i 1.855}$

Hikmatunnisa, M. \& Takwin, B. (2007). Pengaruh perbedaan agama orang tua terhadap psychological wellbeing dan komitmen beragama anak. Jurnal Psikologi Sosial, 2(13), 157-165.

Hoeur, S. (2018). Happiness in the poorest communities: Subjective well-being among adolescent waste pickers in Phnom Penh, Cambodia. Psychological Research, 8(4), 133-144. doi: 10.17265/2159-5542/2018.04.001

Hurlock, E. B. (2009). Psikologi perkembangan suatu pendekatan sepanjang rentang kehidupan. Jakarta: Erlangga

Kemeterian Sosial Republik Indonesia (Kemensos RI). (2018). Pemulung. Diakses melalui https://www.kemsos.go.id/glosarium Lpemulung (pada 7 Februari 2018)

Khiththati. (2008). Para pemulung. Pantau. Diakses melalui https://www.pantau.or.id/?/=d/447 (pada 27 Januari 2018)

Magdalena, D. (2015). Kehidupan seorang pemulung. Kompasiana. Diakses melalui

https://www.kompasiana.com/desy magdalena/kehidupan-seorangpemulung 54f3717d745513932b6c75f e (pada 19 Desember 2017)

Markus, H. R., \& Kitayama, S. (1991). Culture and the self: Implications for the cognition, emotion, and motivation. Psychological Review, 98(2), 224-253. doi: 10.1037/0033295X.98.2.224

Mehnert, T., Krauss, H. H., Nadler, R., \& Boyd, M. (1990). Correlates of life satisfaction in those with disabling conditions. Rehabilitation Psychology, 35(1), 3-17. doi: $10.1037 / \mathrm{h} 0079046$

Miranda, N., \& Amna, Z. (2016). Perbedaan subjective well-being pada dewasa awal ditinjau dari status pernikahan di Kota Banda Aceh. Jurnal Ilmiah Mahasiswa Psikologi, 1(3), 34-43.

Myers, D. G., \& Diener, E. (1995). Who is happy? Psychological Sciences, 6(1), 10$19 . \quad$ doi: $10.1111 / 2 F j .1467-$ 9280.1995.tb00298.x

Nurnaningsih. (2017). Kemiskinan menjadi suatu masalah sosial yang terjadi di kalangan masyarakat. Kompasiana. Diakses melalui https://www.kompasiana.com/nurnn ingsih/kemiskinan-menjadi-suatumasalah-sosial-yang-terjadi-dikalangan-masyarakat 596779fb32386d4a3d320a32 (pada 3 Februari 2018)

Oktaviano, D. (2018). Maulidar, Pahlawan Pendidikan bagi Anak Pemulung di Aceh. Diakses melalui https://foto.kompas.com/photo/detail 2018/03/08/1520483672ba4/1/Maulid ar-Pahlawan-Pendidikan-bagi-AnakPemulung-di-Aceh (pada tanggal 25 Januari 2019)

Pardede, F. (2017). WUF bantu 600 pemulung Medan. Harian Analisa. Diakses melalui http://harian.analisadaily.com/kota/n ews/wuf-bantu-600-pemulungmedan/356193/2017/06/04 (pada 19 Januari 2018)

Permatasari, M., \& Rahdriawan, M. (2013). Kajian keterlibatan pemulung di TPST Bantar Gebang Kota Bekasi. Jurnal Teknik PWK, 2(3), 423-433.

Ramzan, N., \& Rana, S, A. (2014). Expression of gratitude and subjective well-being among university teachers. Middle-East Journal of Scientific Research, 21(5), 756-762. doi: 10.5829/idosi.mejsr.2014.21.05.8464

Sahlan, M. (2012). Pengamatan sosiologis tentang perceraian di Aceh. Jurnal Substantia, 14(1), 88-97.

Samad, S., A., A. (2017). Agama, budaya, dan perubahan sosial perspektif 
pendidikan Islam di Aceh. Jurnal Mudarriuna, 7(1), 23-46. doi: 10.22373/jm.v7i1.1900

Satrio, N. (2014). Masalah ekonomi saat ini. Kompasiana.com. Diakses melalui https://www.kompasiana.com/nicosa trio/54f94772a33311e9018b49ac/masal ah-ekonomi-saat-ini (pada 18 Juli 2019)

Schkade, D. A., \& Kahneman. D. (1998). Does living in California make people happy? A focusing illusion in judgments of life satisfaction. Psychological Science, 9(5), 340-346. doi: $10.1111 / 1467-9280.00066$

Shalih. (2003). Pengemis antara kebutuhan dan penipuan. Jakarta: Darul Falah.

Suhartono. (2015). Sosio kultur pemulung dan perannya dalam keseimbangan lingkungan sekitar dengan mengkategorisasikan barang bekas. Sosio Didaktika, 2(1), 38-49. doi: $\underline{10.15408 / \text { sd.v2i1.1350 }}$
Taufik, I. (2013). Persepsi masyarakat terhadap pemulung di pemukiman TPA Kelurahan Bukit Pinang Kecamatan Samarinda Ulu. Jurnal Sosiologi, 1(4). 85-95.

Umami, K. (2009). Tasawuf Aceh: Merangkai kata damai. Banda Aceh: Katahati Institute.

Utami, S. M. (2009). Keterlibatan dalam kegiatan dan kesejahteraan subjektif mahasiswa. Jurnal Psikologi, 36(2), 144-163. doi: 10.22146/jpsi.7892

Weiten, W. (2008). Psychology themes and variations breifer version. USA. International Student Edition Transdisciplinary Approaches. Hillsdale, NH: Erlbaum.

Wirawan, H. E. (2010). "Kebahagiaan menurut dewasa muda Indonesia" (Laporan tidak dipublikasikan). Universitas Tarumanagara, Jakarta. 